\title{
ESTIMATING THE INFLUENCE OF THE WIND EXPOSURE ON THE MOTION OF AN EXTINGUISHING SUBSTANCE
}

\author{
Yuriy Abramov \\ Research Center ${ }^{1}$ \\ abramov121146@gmail.com \\ Oleksii Basmanov \\ Department of Problems of Civil Protection and Technogenic-Ecological Safety of the Research Center \\ oleksii.basmanov@nuczu.edu.ua \\ Valentina Krivtsova \\ Department of Physical and Mathematical Disciplines ${ }^{1}$ \\ krivtsovav53@gmail.com \\ Andrii Khyzhnyak \\ Department of Automatic Safety Systems and Electrical Installations \\ Cherkasy Institute of Fire Safety named after Chornobyl Heroes of National University of Civil \\ Defence of Ukraine \\ 8 Onoprienko str., Cherkassy, Ukraine, 18034 \\ andrii.khyzhnyak.chipb@gmail.com \\ ${ }^{1}$ National University of Civil Defence of Ukraine \\ 94 Chernyshevska str., Kharkiv, Ukraine, 61023
}

\begin{abstract}
One of the tasks to be solved when deploying fire extinguishing systems is to determine the range of the fire extinguishing agent supply to the combustion center. This problem is solved using data on the trajectory of the fire-extinguishing agent in the combustion center. The presence of wind impact on the process of supplying a fire extinguishing agent will lead to a change in its trajectory. To take into account wind impact, it becomes necessary to assess the result of such impact. Using the basic equation of dynamics for specific forces, a system of differential equations is obtained that describes the delivery of a fire extinguishing agent to the combustion center. The system of differential equations takes into account the presence of wind impact on the movement of the extinguishing agent. The presence of wind action is taken into account by the initial conditions. To solve such a system, the integral Laplace transform was used in combination with the method of undefined coefficients. The solution is presented in parametric form, the parameter of which is time. For a particular case, an expression is obtained that describes the trajectory of the supply of the extinguishing agent into the combustion center. Nomograms are constructed, with the help of which the operative determination of the estimate of the maximum range of the fire-extinguishing agent supply is provided. Estimates are obtained for the time of delivery of a fire-extinguishing agent to the combustion center, and it is shown that for the characteristic parameters of its delivery, this value does not exceed $0.5 \mathrm{~s}$. The influence of wind action on the range of supply of a fire extinguishing agent is presented in the form of an additive component, which includes the value of the wind speed and the square of the time of its delivery. To assess the effect of wind impact on the movement of the fire extinguishing agent, an analytical expression for the relative error was obtained and it was shown that the most severe conditions for supplying the fire extinguishing agent to the combustion center, the value of this error does not exceed $5.5 \%$. Taking into account the wind effect when assessing the range of supply of a fire-extinguishing agent makes it possible to increase the efficiency of fire-extinguishing systems due to its more accurate delivery to the combustion center.
\end{abstract}

Keywords: wind action, equation of dynamics, movement trajectory of a fire extinguishing agent, water jet.

DOI: $10.21303 / 2461-4262.2020 .001400$

\section{Introduction}

One of the ways to reduce the impact of dangerous fire factors on the personnel of operational and rescue units involved in its extinguishing is the use of mobile fire robots [1]. In this case, there are two fundamental possibilities: using the robot in autonomous mode and remote control of it. In the first case, based on the analysis of images in the visible and infrared ranges, the com- 
bustion area is determined and the fire extinguishing agent is supplied [1]. In the second case, the video image is transmitted to the operator, and it determines the point at which the extinguishing agent should be supplied [2]. In both cases, an important task is to accurately supply the extinguishing agent to the target area. This necessitates the construction of a model of the movement of the extinguishing agent, depending on the conditions of its supply (initial speed, vertical angle) and characteristics of the external environment (direction and speed of the wind).

\section{Literature review and problem statement}

The most commonly used extinguishing agent is water. Air resistance has a significant effect on the trajectory of both a continuous jet and an already destroyed one [3]. In work [4], an analytical model was built showing that the range of water supply decreases with an increase in the Froude number in the fire barrel. The influence of the external environment on the behavior of the jet after exiting the wellbore is not considered in this work. In work [5], when developing an autonomous fire extinguishing system to correct deviations of the jet trajectory caused by the wind, video image analysis is used. But models of wind action on the jet trajectory are not considered in this work.

In [6], a model of the trajectory of a water jet was constructed using the Moving Particle Semi-implicit method. At a low initial velocity, the simulation results are in good agreement with the experimental data, while an increase in the initial velocity leads to a significant discrepancy between the calculated and experimental values. To reduce this error, additional adjustments were introduced into the model based on experimental data. The disadvantage of this approach is the limited range of the initial conditions of the jet motion for which such a model is applicable.

In [7], a modified cubic curve is used to predict the jet trajectory. The disadvantage of this approach is that the parameters of such a curve must be determined empirically, and their dependence on the conditions of supply and environmental conditions remains unclear.

In [8], a neural network was used to construct a model of water jet supply. The selection of network parameters was carried out using a genetic algorithm. The disadvantage of this approach is the lack of consideration of the physical processes occurring during the motion of a jet in air, which limits the possibilities of using this class of models. In [9], an experimental study of the trajectories of motion of water jets in still air for the Reynolds numbers of a jet from the range $621 \leq \mathrm{Re}_{d} \leq 1,289$ was carried out. It is shown that the resistance experienced by the jet can be described by the expression $C_{f d}=5 \operatorname{Re}_{d}^{-1 / 2 \pm 0.05}$. In this case, the maximum jet range is achieved at an initial inclination angle $\alpha=35^{\circ}$. In [10], an experimental study of the effectiveness of automatic fire monitors for extinguishing fires in open spaces was carried out. However, this does not take into account the influence of the external environment on the trajectories of the water jet.

In the experimental work [11], using a high-speed video camera, the effect of pressure on the characteristics of the jet, including the distance of its delivery, was investigated. In [12], a three-dimensional simulation model of water supply from a fire monitor for extinguishing a tank with fuel oil was built. The disadvantage of the model is that it is applicable for reservoirs with a diameter of 34-100 m and a height of 10-20 m. A mathematical model of the extinguishing process with a continuous water jet was constructed in [13]. Simulation tests were carried out for various angles of inclination and water flow rates of the fire barrel. It should be noted that recently there has been a significant increase in interest in the use of robots for emergency response and, in particular, for extinguishing fires [14]. Such robots are equipped with high-speed fire monitors [15], with the help of which it is possible to control the supply of a stream of extinguishing agent in space. In [16], a mathematical model is presented in relation to such a variant of controlling a stream of extinguishing agent, which takes into account the resistance of the air environment. In [17], a model of the trajectory of movement of a fire extinguishing agent using gel-forming compositions is considered. However, the model does not take into account the effect of wind action. In [18], the influence of various design parameters of the fire monitor on the characteristics of the jet is considered. However, modeling only indicates a satisfactory agreement with experimental data.

In [19], an experimental study of the range of supply of aerated jets directed at an angle of $45^{\circ}$ to the horizon was carried out. The presence of aeration leads to an earlier destruction of 
the jet, a decrease in its velocity and separation into droplets. As a result, the significance of the influence of the characteristics of the external environment on the trajectory of the jet increases. But this issue has not been studied in the work. The paper [20] considers the option of using an unconventional fire extinguishing agent, in particular, liquid nitrogen. The construction of the trajectory of such a fire extinguishing agent is fraught with serious difficulties associated with the evaporation of liquid nitrogen.

A common disadvantage of all the considered works is that the effect of wind on the trajectory of the jet has not been considered. At the same time, for extinguishing fires in open spaces, in mines, in tunnels, in the metro and other similar structures, the influence of the speed of movement of the air (conditionally the effect of wind) can't be neglected. In this regard, one of the problems is to take into account the effect of the wind on the movement of the water jet after leaving the fire barrel. In this case, it is especially important to have the data necessary for an a priori assessment of this effect of wind action. The latter circumstance is due to the need to develop tactics for using fire extinguishing means, which is carried out in advance for each object. For this purpose, mathematical models can be used that describe the process of delivering a fire extinguishing agent to the combustion center, and which take into account the specifics of fire extinguishing. One of the specific features is the fact that the vector of wind action for the considered fire extinguishing conditions is collinear to the direction of supply of the extinguishing agent. This is due to both the specifics of the objects where fire extinguishing occurs (mines, tunnels, etc.), and the fact that fire robots (especially stationary ones) are oriented in space, taking into account the wind phase.

\section{The aim and objectives of research}

The aim is to determine the effect of wind action on the movement of a fire extinguishing agent jet when it is fed into the combustion center for conditions when the wind action vector and the direction of supply are collinear.

To achieve this aim, it is necessary to solve the following objectives:

- to obtain a mathematical description for the trajectory of the fire extinguishing agent in a parametric form;

- to obtain estimates for the maximum range of supply and the time of supply of the extinguishing agent to the combustion center;

- to obtain an estimate characterizing the effect of wind action on the movement of a fire-extinguishing agent when it is delivered to the source of combustion.

\section{Models of fire extinguishing agent movement and assessment of wind influence}

Let's consider the movement of the extinguishing agent in the Cartesian coordinate system xoy in the section from the mobile fire unit to the combustion center (Fig. 1).

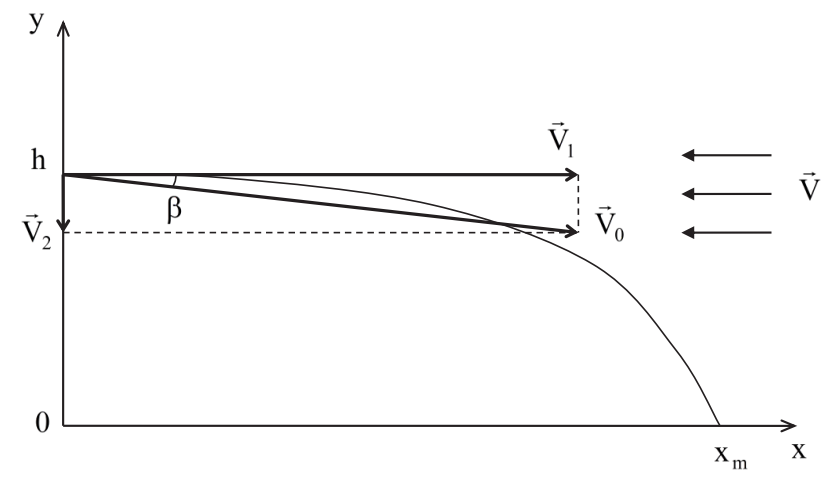

Fig. 1. To the movement of the extinguishing agent

The extinguishing agent is supplied to the combustion center at an initial velocity $\vec{V}_{0}$ from a height $h$. In the general case, when a fire extinguishing agent is supplied, there is a wind effect, the velocity of which $\vec{V} ; x_{m}$ - the maximum range of the extinguishing agent supply. 
In accordance with the basic equation of dynamics as applied to specific forces, the movement of the extinguishing agent is described by a system of differential equations

$$
\begin{gathered}
\frac{\mathrm{d}^{2} x}{\mathrm{~d} t^{2}}+\alpha\left(\frac{\mathrm{d} x}{\mathrm{~d} t}+\sigma V\right)=0 \\
\frac{\mathrm{d}^{2} y}{\mathrm{~d} t^{2}}+\alpha \frac{\mathrm{d} y}{\mathrm{~d} t}=-g
\end{gathered}
$$

with initial conditions

$$
\begin{gathered}
x(0)=0 ; \\
y(0)=h ; \\
\frac{\mathrm{d} x(0)}{\mathrm{d} t}=V_{1}=V_{0} \cos \beta ; \frac{\mathrm{d} y(0)}{\mathrm{d} t}=-V_{2}=-V_{0} \sin \beta,
\end{gathered}
$$

where $g$ - acceleration of gravity; $\alpha$ - resistance coefficient; $\sigma= \pm 1$ - coefficient taking into account the wind direction.

To solve system (1) with initial conditions (2), let's apply the Laplace integral transform to the system of differential equations (1), as a result of which let's obtain

$$
\begin{gathered}
X(p)=\left(p V_{1}-\alpha \sigma V\right)\left[p^{2}(p+\alpha)\right]^{-1} ; \\
Y(p)=\left[p(p+\alpha) h-V_{2} p-g\right]\left[p^{2}(p+\alpha)\right]^{-1},
\end{gathered}
$$

where $X(p)=L[x(t)] ; Y(p)=L[y(t)] ; L-$ the operator of the integral Laplace transform.

If to use the method of undefined coefficients, then expressions (3) will be transformed to the form

$$
\begin{gathered}
X(p)=\left(V_{1}+\sigma V\right) \alpha^{-1}\left[p^{-1}-(p+\alpha)^{-1}\right]-\sigma V p^{-2} \\
Y(p)=h p^{-1}-g\left(\alpha p^{2}\right)^{-1}-\left(V_{2} \alpha-g\right) \alpha^{-2}\left[p^{-1}-(p+\alpha)^{-1}\right] .
\end{gathered}
$$

Applying the inverse integral Laplace transform to (4), let's obtain a solution to system (1) with the initial conditions (2)

$$
\begin{gathered}
x(t)=\alpha^{-1}\left(V_{1}+\sigma V\right)[1-\exp (-\alpha t)]-\sigma V t ; \\
y(t)=h-g \alpha^{-1} t-\left(V_{2} \alpha-g\right) \alpha^{-2}[1-\exp (-\alpha t)] .
\end{gathered}
$$

Expressions (5) describe the trajectory of the fire extinguishing agent at the site of its delivery to the combustion center in a parametric form.

Fig. 2 shows an example of the trajectories of the fire extinguishing agent movement to the combustion center for the case $h=1,0 \mathrm{~m}, \beta=0, \alpha=0,2 \mathrm{~s}^{-1} ; V_{0}=25 \mathrm{~m} \times \mathrm{s}^{-1}$.

Let's consider the particular case when $\beta=V=0$. For such a case, it is possible to obtain an explicit analytical expression describing the trajectory $y=y(x)$ of the fire extinguishing agent movement.

For this, from the expression for $x(t)$ from (5), it is possible to write

$$
1-\exp (-\alpha t)=\alpha x V_{0}^{-1}
$$

whence the expression for time follows 


$$
t=-\alpha^{-1} \ln \left(1-\alpha x V_{0}^{-1}\right)
$$

After substituting (6) and (7) into the expression for $y(t)$ from (5) let's finally obtain

$$
y=h+\left(V_{0} \alpha\right)^{-1} g x+g \alpha^{-2} \ln \left(1-\alpha x V_{0}^{-1}\right)
$$

Let's determine the maximum range $x_{m}$ of the extinguishing agent supply. For this purpose, let's rewrite (8) as follows

$$
y=h+g \alpha^{-2}[z+\ln (1-z)]
$$

where $z=\alpha V_{0}^{-1} x_{m}$.

The quantity $z$ for a given a priori value of the parameter $\alpha$ is determined by the solution of the transcendental equation

$$
f(z)+h=0,
$$

where $f(z)=g \alpha^{-2}[z+\ln (1-z)]$

If $\alpha=(0.15 \div 0.45) \mathrm{s}^{-1} ; h=(1.0 \div 1.5)$, then solutions for $(10)$ can be represented as

$$
z=a_{0}+a_{1} h
$$

where $a_{i}$-parameters depending on the quantity $\alpha$. Fig. 3 shows the dependences $a_{0}=a_{0}(\alpha)$ and $a_{1}=a_{1}(\alpha)$.

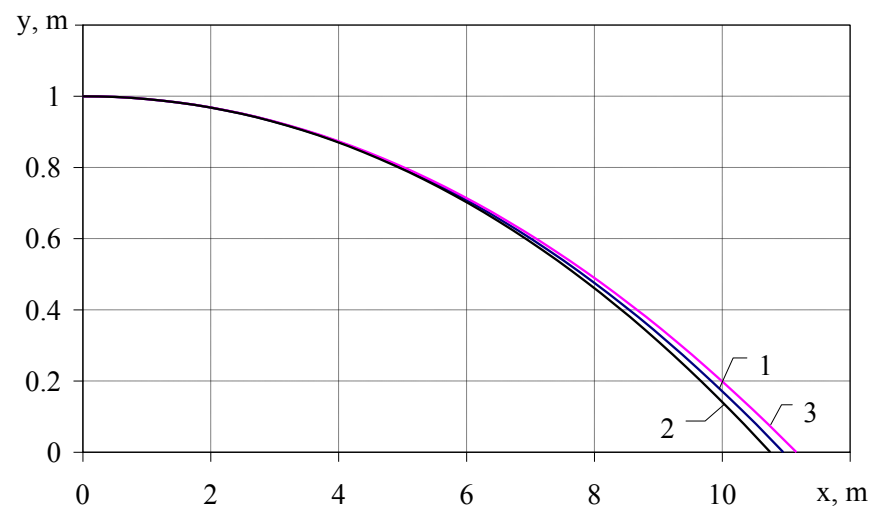

Fig. 2. The trajectory of movement of the extinguishing agent: $1-V=0 ; 2-V=10 \mathrm{~m} \times \mathrm{s}^{-1}$ (headwind); $3-V=10 \mathrm{~m} \times \mathrm{s}^{-1}$ (tailwind)

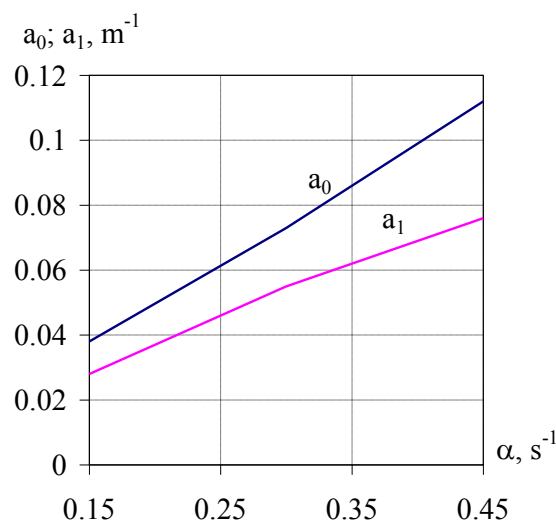

Fig. 3. Dependencies $a_{0}=a_{0}(\alpha)$ and $a_{1}=a_{1}(\alpha)$ 
To determine the maximum range $x_{m}$ of the extinguishing agent supply, the expression

$$
x_{m}=V_{0} \alpha^{-1} z
$$

In practical applications, it is advisable to use a graphical interpretation of the dependence (12). As an example, Fig. 4, 5 shows such a graphical interpretation in the form of nomograms built for $\alpha=0.15 \mathrm{~s}^{-1}$.

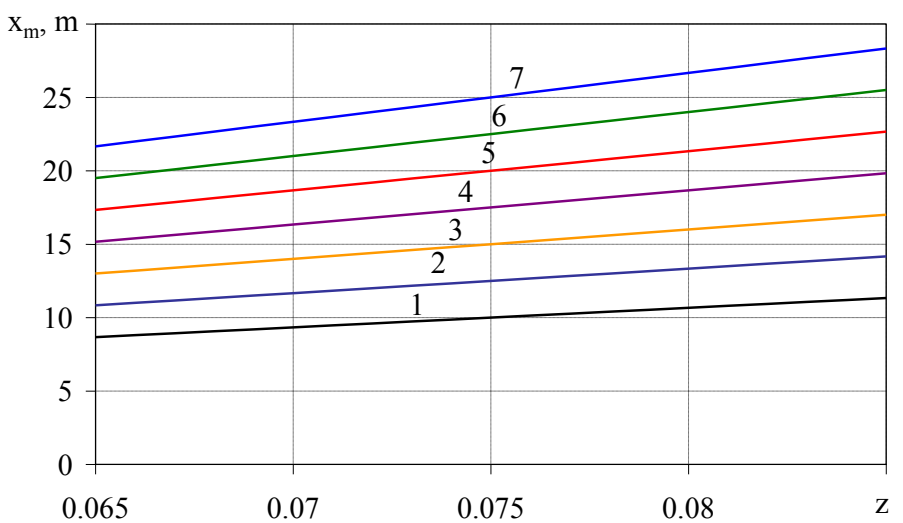

Fig. 4. Nomogram $x_{m}=x_{m}(z): 1-V_{0}=20 \mathrm{~ms}^{-1} ; 2-V_{0}=25 \mathrm{~ms}^{-1} ; 3-V_{0}=30 \mathrm{~ms}^{-1} ; 4-V_{0}=35 \mathrm{~ms}^{-1}$; $5-V_{0}=40 \mathrm{~ms}^{-1} ; 6-V_{0}=45 \mathrm{~ms}^{-1} ; 7-V_{0}=50 \mathrm{~ms}^{-1}$

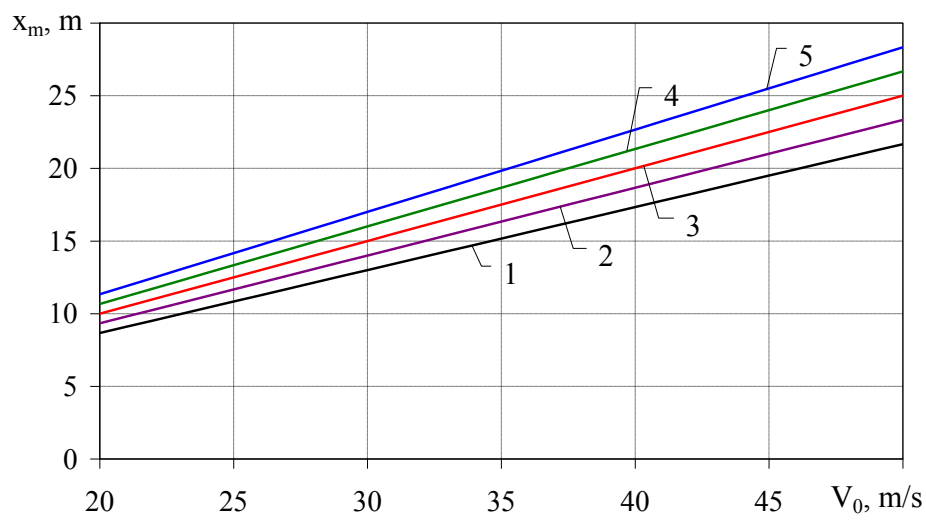

Fig. 5. Nomogram $x_{m}=x_{m}\left(V_{0}\right): 1-z=0.065 ; 2-z=0.07 ; 3-z=0.075 ; 4-z=0.08 ; 5-z=0.085$

The parameter $z$ on the nomograms is determined based on expression (11), as well as the dependences shown in Fig. 3.

The delivery time $t_{0}$ of the extinguishing agent to the combustion center is determined by solving the equation

$$
y\left(t_{0}\right)=0
$$

which in expanded form has the form

$$
h-g \alpha^{-1} t_{0}+g \alpha^{-2}\left[1-\exp \left(-\alpha t_{0}\right)\right]=0 .
$$

Considering that

$$
\exp \left(-\alpha t_{0}\right) \cong 1-\alpha t_{0}+0,5\left(\alpha t_{0}\right)^{2}
$$

then equation (14) will be transformed to the form 


$$
h-0.5 g t_{0}^{2}=0,
$$

which solution is

$$
t_{0}=\left(2 h g^{-1}\right)^{0.5}
$$

For $h=1.0 \mathrm{~m}$, the value of $t_{0}$ is $0.45 \mathrm{~s}$.

The maximum range $x_{m}$ of the fire extinguishing agent supply, taking into account (5) and (15), can be represented as dependence

$$
x_{m}=V_{0} t_{0}\left(1-0.5 \alpha t_{0}\right)-0.5 V t_{0}^{2} .
$$

The second term in this dependence describes the effect of wind on the range of supply of the extinguishing agent. Then the relative error due to the influence of wind action can be described by the expression

$$
\delta=0.5 \alpha V t_{0}\left[V_{0}\left(1-0.5 \alpha t_{0}\right)\right]^{-1} \cong 0.5 \alpha \gamma t_{0}\left(1+0.5 \alpha t_{0}\right)
$$

where $\gamma=V \times V_{0}^{-1}$

In Fig. 6 for $h=1.0 \mathrm{~m}$ shows a graphical dependence $\delta(\gamma, \alpha)$.

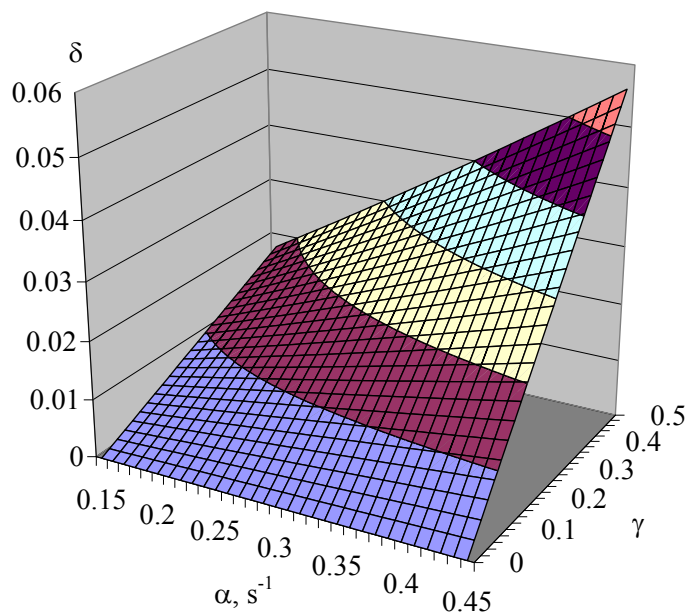

Fig. 6. Dependence $\delta(\gamma, \alpha)$

An analysis of this dependence shows that for the considered values of the parameters, the value of the relative error $\delta$ does not exceed $5.5 \%$.

\section{Discussion of the results}

Using the basic equation of dynamics as applied to specific forces, and also under the assumption that the direction of supply of the extinguishing agent and the vector of wind action are collinear, a linear version of the system of differential equations is obtained that describes the movement of the extinguishing agent. To solve such a system of differential equations, the integral Laplace transform was used in combination with the method of undefined coefficients. The result of this approach is the representation of a solution that describes the trajectory of the fire extinguishing agent in a parametric form in the form (5). The solution of the system of equations (1) in the form (5) is a mathematical model of the trajectory of delivery of the extinguishing agent to the lesion focus. This model allows a priori to solve the problem of tactical fire extinguishing at such objects as mines, tunnels, metro, etc. In particular, the use of this model allows to obtain the initial data on the range of deployment of fire robots or at their location. 
However, the use of this model presupposes carrying out computational procedures, which is not always advisable or possible in practice. Therefore, the results obtained make it possible to exclude the computational procedure and use the following algorithm to take into account the wind when determining the maximum range of the fire extinguishing agent supply.

Using nomograms, which are constructed for the case when $\beta=V=0$ (the condition when $\beta=0$ is typical for the use of fire robots), the value of the parameter $x_{m}$ is determined. Then, after obtaining information about the magnitude of the wind speed, the magnitude of the error caused by the wind action is estimated (for this purpose, the dependence shown in Fig. 6 is used). The magnitude of this error, as well as its sign (which takes into account the direction of the wind - Fig. 2) is used to determine the additive component of the maximum range of supply of the extinguishing agent. To estimate the time of delivery of the extinguishing agent to the combustion center, an analytical expression was obtained in the form (17). The influence of wind action on the range of supply of a fire extinguishing agent is presented in the form of an additive component, which includes the value of the wind speed and the square of the time of its delivery. The maximum value of the relative error characterizing the effect of wind action for the characteristic parameters of the movement of the extinguishing agent does not exceed $5.5 \%$.

\section{Conclusions}

A model of the movement of a fire-extinguishing agent is constructed, it is provided that the direction of its supply and the vector of wind action are collinear. Using the integral Laplace transform and the method of undefined coefficients, a mathematical description for the trajectory of the fire extinguishing agent in a parametric form is obtained. A feature of this description is that time is used as a parameter.

The values for the maximum range of the fire-extinguishing agent supply and the time of its supply, which are respectively equal to $10.0 \mathrm{~m}$ and $0.5 \mathrm{~s}$, have been obtained.

It is shown that the influence of wind action during the movement of a fire extinguishing agent is manifested in a change in the distance of its delivery. In this case, the modulus of the relative error in determining the value of the maximum range of delivery of the extinguishing agent does not exceed $5.5 \%$ for the most severe conditions.

\section{References}

[1] McNeil, J. G., Lattimer, B. Y. (2016). Robotic Fire Suppression Through Autonomous Feedback Control. Fire Technology, 53 (3), 1171-1199. doi: https://doi.org/10.1007/s10694-016-0623-1 1

[2] Wu, H. B., Li, Z. J., Ye, J. H., Ma, S. C., Li, J. W., Yang, X. N. (2016). Firefighting robot with video full-closed loop control. International Journal of Safety and Security Engineering, 6 (2), 254-269. doi: https://doi.org/10.2495/safe-v6-n2254-269 2

[3] Zhang, M., Liu, X., Wang, X., Wang, Y., Liang, W. (2019). Fire Water Monitor Trajectories Based on Turbulence Breakup Model. Journal of Testing and Evaluation, 48 (6), 20180428. doi: https://doi.org/10.1520/jte20180428 3

[4] Trettel, B., Ezekoye, O. A. (2015). Theoretical Range and Trajectory of a Water Jet. Volume 7A: Fluids Engineering Systems and Technologies. doi: https://doi.org/10.1115/imece2015-52103

[5] McNeil, J. G., Lattimer, B. Y. (2016). Autonomous Fire Suppression System for Use in High and Low Visibility Environments by Visual Servoing. Fire Technology, 52 (5), 1343-1368. doi: https://doi.org/10.1007/s10694-016-0564-8

[6] Zhu, J., Li, W., Lin, D., Zhao, G. (2018). Study on Water Jet Trajectory Model of Fire Monitor Based on Simulation and Experiment. Fire Technology, 55 (3), 773-787. doi: https://doi.org/10.1007/s10694-018-0804-1 4

[7] Chong, W., Hu, Y., Yuan, D., Ma, Y. (2016). Jet Trajectory Recognition Based on Dark Channel Prior. Intelligent Visual Surveillance, 147-153. doi: https://doi.org/10.1007/978-981-10-3476-3_18

[8] Zhang, C., Zhang, R., Dai, Z., He, B., Yao, Y. (2019). Prediction model for the water jet falling point in fire extinguishing based on a GA-BP neural network. PLOS ONE, 14 (9), e0221729. doi: https://doi.org/10.1371/journal.pone.0221729 5

[9] Comiskey, P. M., Yarin, A. L. (2018). Friction coefficient of an intact free liquid jet moving in air. Experiments in Fluids, 59 (4). doi: https://doi.org/10.1007/s00348-018-2519-y 6 
[10] Xin, Y., Thumuluru, S., Jiang, F., Yin, R., Yao, B., Zhang, K., Liu, B. (2013). An Experimental Study of Automatic Water Cannon Systems for Fire Protection of Large Open Spaces. Fire Technology, 50 (2), 233-248. doi: https://oi.org/10.1007/ s10694-013-0363-4

[11] Liu, X., Wang, J., Li, B., Li, W. (2019). Experimental study on jet flow characteristics of fire water monitor. The Journal of Engineering, 2019 (13), 150-154. doi: https://doi.org/10.1049/joe.2018.8950 7

[12] Miyashita, T., Sugawa, O., Imamura, T., Kamiya, K., Kawaguchi, Y. (2014). Modeling and analysis of water discharge trajectory with large capacity monitor. Fire Safety Journal, 63, 1-8. doi: https://doi.org/10.1016/j.firesaf.2013.09.028

[13] Gałaj, J., Drzymała, T., Šukys, R., Tofiło, P. (2018). A computer model designed to evaluate the firefighting effectiveness of solid jet produced by water nozzle. Journal of Civil Engineering and Management, 24 (1), 1-10. doi: https://doi.org/10.3846/ jcem.2018.256 8

[14] Abramov, Yu. O., Sobyna, V. O., Kryvtsova, V. I., Tyshchenko, Ye. O., Sokolov, D. A. (2018). Pat. No. 133256 UA. Sposib hasinnia pozhezhi mobilnym pozhezhnym robotom. No. 201811148; declareted: 12.11.2018; published: 25.03.2019, Bul. No. 6.9

[15] Abramov, Yu. O., Basmanov, O. Ye., Salamov, D. O., Tyshchenko, Ye. O. (2017). Pat. No. 122938 UA. Pozhezhnyi monitor. No. 201710046; declareted: 17.10.2017; published: 25.01.2018, Bul. No. 2.10

[16] Abramov, Y., Basmanov, O., Salamov, J., Mikhayluk, A., Yashchenko, O. (2019). Developing a model of tank cooling by water jets from hydraulic monitors under conditions of fire. Eastern-European Journal of Enterprise Technologies, 1 (10 (97)), 14-20. doi: https://doi.org/10.15587/1729-4061.2019.154669 11

[17] Strelec, V., Senchykhin, Y., Ostapov, K., Sirovoj, V. (2018). Analysis of the process of feeding the gel-forming compositions. Problemy pozharnoy bezopasnosti, 44, 137-147.12

[18] Xu, M., Zhang, X., Hu, G., Li, G. (2016). The structure design and flow field simulation of a fire water monitor driven by worm gear with bevel gear. Machine Tool \& Hydraulics, 6. Available at: http://en.cnki.com.cn/Article_en/CJFDTotal-JCYY201606011.htm13

[19] Zhang, W., Zhu, D. Z. (2015). Far-field properties of aerated water jets in air. International Journal of Multiphase Flow, 76, 158-167. doi: https://doi.org/10.1016/j.jijmultiphaseflow.2015.07.006

[20] Hou, Y., Yang, X., Ren, F., Liu, Y. (2018). Structural Analysis and Optimization of Liquid Nitrogen Fire Monitor Based on FLUENT. Proceedings of the 2018 3rd International Conference on Electrical, Automation and Mechanical Engineering (EAME 2018). doi: https://doi.org/10.2991/eame-18.2018.62

Received date 13.01.2020

Accepted date 26.08.2020

Published date 30.09.2020
(C) The Author(s) 2020

This is an open access article under the CC BY license (http://creativecommons.org/licenses/by/4.0). 